Louisiana State University

LSU Digital Commons

8-9-2010

\title{
Large inverse magnetic entropy changes and magnetoresistance in the vicinity of a field-induced martensitic transformation in Ni50-x Cox Mn32-y Fey Ga18
}

\author{
Arjun K. Pathak \\ Southern Illinois University Carbondale \\ Igor Dubenko \\ Southern Illinois University Carbondale \\ Haluk E. Karaca \\ University of Kentucky \\ Shane Stadler \\ Louisiana State University \\ Naushad Ali \\ Southern Illinois University Carbondale
}

Follow this and additional works at: https://digitalcommons.Isu.edu/physics_astronomy_pubs

\section{Recommended Citation}

Pathak, A., Dubenko, I., Karaca, H., Stadler, S., \& Ali, N. (2010). Large inverse magnetic entropy changes and magnetoresistance in the vicinity of a field-induced martensitic transformation in Ni50-x Cox Mn32-y Fey Ga18. Applied Physics Letters, 97 (6) https://doi.org/10.1063/1.3467460 
Southern Illinois University Carbondale

OpenSIUC

Publications

Department of Physics

$8-2010$

Large Inverse Magnetic Entropy Changes and Magnetoresistance in the Vicinity of a FieldInduced Martensitic Transformation in Ni50-xCoxMn32-yFeyGa18

Arjun K. Pathak

Southern Illinois University Carbondale

Igor Dubenko

Southern Illinois University Carbondale

Haluk E. Karaca

University of Kentucky

Shane Stadler

Louisiana State University

Naushad Ali

Southern Illinois University Carbondale

Follow this and additional works at: http://opensiuc.lib.siu.edu/phys_pubs

(C) 2010 American Institute of Physics

Published in Applied Physics Letters, Vol. 97 No. 6 (2010) at doi: 10.1063/1.3467460

\section{Recommended Citation}

Pathak, Arjun K., Dubenko, Igor, Karaca, Haluk E., Stadler, Shane and Ali, Naushad. "Large Inverse Magnetic Entropy Changes and Magnetoresistance in the Vicinity of a Field-Induced Martensitic Transformation in Ni50-xCoxMn32-yFeyGa18." (Aug 2010).

This Article is brought to you for free and open access by the Department of Physics at OpenSIUC. It has been accepted for inclusion in Publications by an authorized administrator of OpenSIUC. For more information, please contact opensiuc@lib.siu.edu. 


\title{
Large inverse magnetic entropy changes and magnetoresistance in the vicinity of a field-induced martensitic transformation in $\mathrm{Ni}_{50-x} \mathrm{Co}_{\mathrm{x}} \mathrm{Mn}_{32-\mathrm{y}} \mathrm{Fe}_{\mathrm{y}} \mathrm{Ga}_{18}$
}

\author{
Arjun K. Pathak, ${ }^{1, a)}$ Igor Dubenko, ${ }^{1}$ Haluk E. Karaca, ${ }^{2}$ Shane Stadler, ${ }^{3}$ and Naushad $\mathrm{Ali}^{1}$ \\ ${ }^{1}$ Department of Physics, Southern Illinois University, Carbondale, Illinois 62901, USA \\ ${ }^{2}$ Department of Mechanical Engineering, University of Kentucky, Lexington, Kentucky 40506, USA \\ ${ }^{3}$ Department of Physics and Astronomy, Louisiana State University, Baton Rouge, Louisiana 70803, USA
}

(Received 23 May 2010; accepted 1 July 2010; published online 12 August 2010)

\begin{abstract}
Significantly large inverse magnetic entropy changes $\left(\Delta \mathrm{S}_{\mathrm{M}}\right)$ and magnetoresistance (MR) were observed at the inverse martensitic phase transitions of the Ga-based magnetic shape memory Heusler alloys: $\mathrm{Ni}_{50-\mathrm{x}} \mathrm{Co}_{\mathrm{x}} \mathrm{Mn}_{32-\mathrm{y}} \mathrm{Fe}_{\mathrm{y}} \mathrm{Ga}_{18}$. The crystal structures of alloys were tetragonal at $300 \mathrm{~K}$ and the phase transition temperatures and magnetic properties were found to be correlated with the degree of tetragonal distortion. The maximum peak values of the $\Delta \mathrm{S}_{\mathrm{M}}$ and $\mathrm{MR}$ at $\mathrm{H}=5 \mathrm{~T}$ were determined as $\approx(+) 31 \mathrm{~J} \mathrm{Kg}^{-1} \mathrm{~K}^{-1}$ and $\approx-21 \%$, respectively, for $\mathrm{x}=8$ and $\mathrm{y}=2$. The relatively small hysteretic loss and large refrigeration capacity observed in this system make these compounds promising materials for applications. (C) 2010 American Institute of Physics.

[doi:10.1063/1.3467460]
\end{abstract}

The unusual magnetic properties of ferromagnetic $\mathrm{Ni}-\mathrm{Mn}-\mathrm{X}(\mathrm{X}=\mathrm{In}, \mathrm{Sn}, \mathrm{Sb}$, and $\mathrm{Ga})$ based Heusler alloys have attracted the attention of the scientific community. It has been shown that field- and temperature-induced reverse martensitic transformations can be observed in $\mathrm{Ni}-\mathrm{Mn}-\mathrm{In} / \mathrm{Sn} / \mathrm{Sb}{ }^{1-3}$ This transformation originates from the large difference in magnetization $(\Delta \mathrm{M})$ between the parent and the martensite phases and is associated with large inverse magnetocaloric effects (MCE), magnetoresistance (MR), shape memory effects, and giant Hall effects. ${ }^{1-3}$ The search for such multifunctional compounds is essential for both fundamental science and technological applications. Unlike the $\mathrm{Ni}-\mathrm{Mn}-\mathrm{In} / \mathrm{Sn} / \mathrm{Sb}$ systems, the martensitic and austenitic phases of $\mathrm{Ni}_{2} \mathrm{MnGa}$ are both ferromagnetic and characterized by a small $\Delta \mathrm{M}$. Stoichiometric $\mathrm{Ni}_{2} \mathrm{MnGa}$ is a typical ferromagnetic shape memory alloy that passes from a low-symmetry, ferromagnetic martensitic phase to a ferromagnetic austenitic phase at the martensitic transition temperature $\left(\mathrm{T}_{\mathrm{M}}=202 \mathrm{~K}\right)$, and transforms to a PM state above the Curie temperature $\left(\mathrm{T}_{\mathrm{C}}=376 \mathrm{~K}\right){ }^{4}$

Recently, it has been shown that changing the composition of the Ga-based Heusler alloys can also result in a significant difference between the magnetization of the austenitic and martensitic phases, and in field-induced reverse martensitic transformations. ${ }^{5-7}$ Therefore, large MR and MCE can also be expected to be observed in Ga-based Heusler alloys. In this paper, we have studied the MR and MCE of $\mathrm{Ni}_{50-\mathrm{x}} \mathrm{Co}_{\mathrm{x}} \mathrm{Mn}_{32-\mathrm{y}} \mathrm{Fe}_{\mathrm{y}} \mathrm{Ga}_{18}$. We report significantly large inverse MCE and MR that are uniquely characterized by small hysteresis effects for optimum choices of $\mathrm{x}$ and $\mathrm{y}$. Magnetic phase diagrams were constructed and described in terms of electron concentration, degree of tetragonal distortion and average metallic radii.

Approximately $5 \mathrm{~g}$ of polycrystalline $\mathrm{Ni}_{50-\mathrm{x}} \mathrm{Co}_{\mathrm{x}} \mathrm{Mn}_{32-\mathrm{y}}$ $\mathrm{Fe}_{\mathrm{y}} \mathrm{Ga}_{18}$ alloys with $\mathrm{x}=0.0$ and 8.0, and $\mathrm{y}=0.0,1.0,1.5$, and 2.0 were prepared by conventional arc melting in an argon

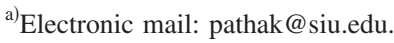

atmosphere using high purity elements: Ni (99.9\%); $\mathrm{Mn}$ (99.99\%), Co (99.9\%), Fe (99.9\%), and Ga (99.999\%). The arc melted samples were wrapped in tantalum foil and annealed in high vacuum $\left(\approx 10^{-4}\right.$ torr) for $72 \mathrm{~h}$ at $850{ }^{\circ} \mathrm{C}$, and slowly cooled down to room temperature. The phase purity and crystal structures were determined by powder x-ray diffraction using $\mathrm{Cu} \mathrm{K} \alpha$ radiation. The magnetic properties were measured in the temperature range 5-400 K, and in magnetic fields of up to $5 \mathrm{~T}$, using a superconducting quantum interference device magnetometer (Quantum Design, Inc.). Magnetotransport measurements were carried out using a standard four-probe technique. Magnetotransport measurements were carried out during heating and cooling [zero field cooled (ZFC) and field cooled cooling (FCC) measurements] of the samples that were initially cooled from 400 to $5 \mathrm{~K}$ under zero magnetic field. The transition temperatures were determined from the local maxima of $\mathrm{dM} / \mathrm{dT}$ of the ZFC $\mathrm{M}(\mathrm{T})$ curves. MR has been calculated as $\mathrm{MR}=[\rho(\mathrm{H}, \mathrm{T})$ $-\rho(0)] / \rho(0)] \times 100 \%$, where $\rho(\mathrm{H}, \mathrm{T})$ is the resistivity of the sample at temperature $\mathrm{T}$, and an applied magnetic field $\mathrm{H}$. The $\Delta \mathrm{S}_{\mathrm{M}}(\mathrm{T}, \mathrm{H})$ was estimated from isothermal magnetization curves using a Maxwell relation., ${ }^{2,8}$ The refrigeration capacity (RC) was calculated by integrating the $\Delta \mathrm{S}_{\mathrm{M}}(\mathrm{T}, \mathrm{H})$ curves over the full width at half maximum (FWHM). ${ }^{2,8}$

As shown in Figs. 1(a)-1(e), all of the alloys are in the martensite phase at room temperature and possess $14 / \mathrm{mmm}$ tetragonal structure. For $\mathrm{x}=8$ and $\mathrm{y}=2$, the sample was found to be in mixed martensitic and austenitic phases [the austenitic phase is indicated by asterisks, see Fig. 1(e)]. The lattice parameters $\mathrm{a}=\mathrm{b}$ and $\mathrm{c}$ were found to increase and decrease, respectively, with increasing average metallic radii $\left(\mathrm{R}_{\mathrm{av}}\right)$ [see Fig. 1(f)]. ${ }^{9}$ The c/a ratio was found to decrease with increasing in $\mathrm{R}_{\mathrm{av}}$ (data not shown in Fig. 1).

As shown in (M) $\mathrm{T}$ for $\mathrm{x}=0$ and $\mathrm{y}=0$, the sample possesses only a single transition at $360 \mathrm{~K}$ within the upper temperature limit of $400 \mathrm{~K}$ [see Fig. 2(a)]. This, together with the room temperature $\mathrm{XRD}$, revealed that this transition observed in magnetization curve is due to the Curie tempera- 


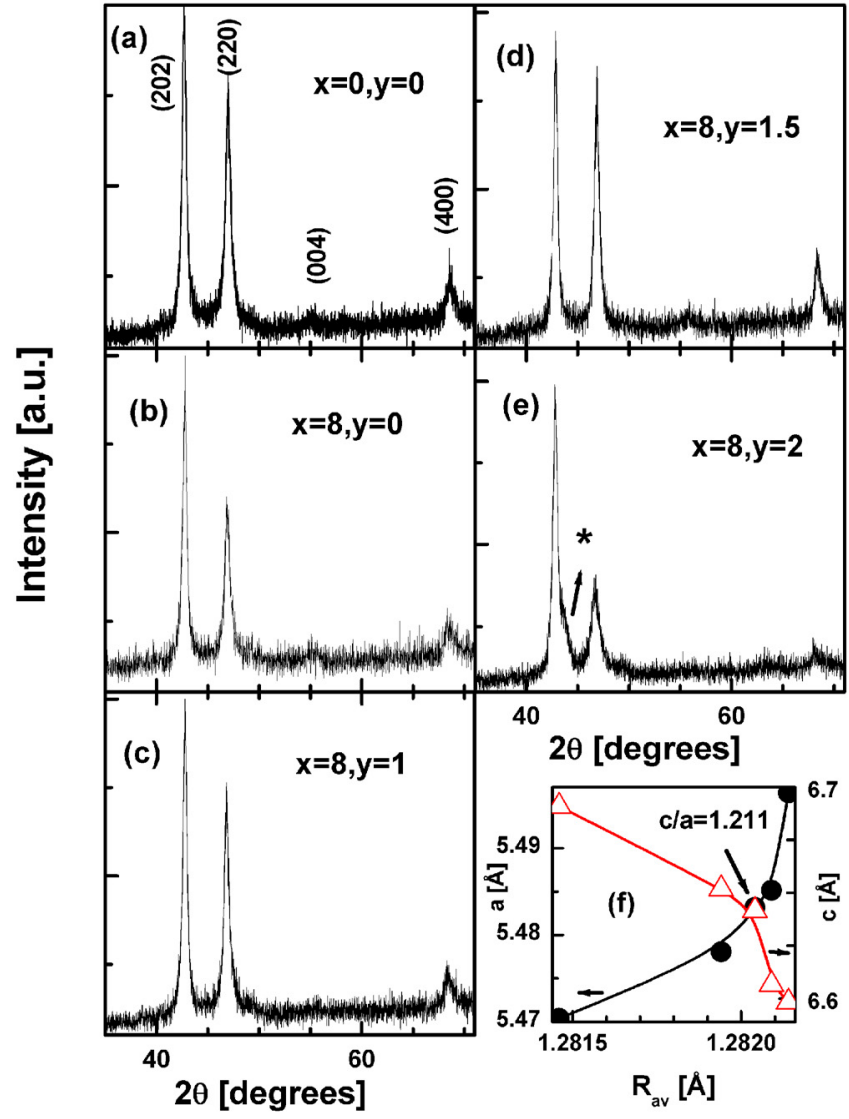

FIG. 1. (Color online) [(a)-(e)] Room temperature x-ray diffraction (XRD) patterns of $\mathrm{Ni}_{50-\mathrm{x}} \mathrm{Co}_{\mathrm{x}} \mathrm{Mn}_{32-\mathrm{y}} \mathrm{Fe}_{\mathrm{y}} \mathrm{Ga}_{18}$ and (f) tetragonal cell parameters as a function of average metallic radii.

ture of martensitic phase. Therefore, the phase transition temperatures $T_{M}$ and $T_{C}$ of the austenitic phase for $x=y=0$ are above $400 \mathrm{~K}$. When $16 \%$ of the $\mathrm{Ni}$ was replaced by Co in $\mathrm{Ni}_{50} \mathrm{Mn}_{32} \mathrm{Ga}_{18}$, the sample $\left(\mathrm{Ni}_{42} \mathrm{Co}_{8} \mathrm{Mn}_{32} \mathrm{Ga}_{18}\right)$ exhibited the following magnetic phases: (i) a ferromagnetic (FM) martensitic phase below $\mathrm{T}_{\mathrm{CM}}=276 \mathrm{~K}$; (ii) a low magnetic state [antiferromagnetic (AFM) or paramagnetic (PM)] in the intermediate temperature interval $\mathrm{T}_{\mathrm{CM}}<\mathrm{T}<\mathrm{T}_{\mathrm{M}}$; and (iii) a ferromagnetic austenitic phase above $\mathrm{T}_{\mathrm{M}}$. While cooling [FCC M(T) in Fig. 2(a)] the sample returns to a low magnetic state through the reverse martensitic transformation. A temperature hysteresis in ZFC and FCC curves at $T_{M}$ is the indicative of a temperature-induced first order transition (FOT). As shown in Fig. 2(a), the transition temperatures can be tuned by the substitution of $\mathrm{Fe}$ in the $\mathrm{Mn}$ position. Recent polarization analysis experiments in $\mathrm{Ni}-\mathrm{Mn}-\mathrm{Sb} / \mathrm{Sn}$ suggest that the low magnetic state (for $\mathrm{x}=8$ ) at $\mathrm{T}_{\mathrm{CM}}<\mathrm{T}<\mathrm{T}_{\mathrm{M}}$ is AFM. ${ }^{10}$ Therefore the sharp jump of magnetization at $\mathrm{T}_{\mathrm{M}}$ in $\mathrm{Ni}_{42} \mathrm{Co}_{8} \mathrm{Mn}_{32} \mathrm{Ga}_{18}$ could be due to a FOT from a martensitic AFM phase to a FM austenitic phase. A large shift in $T_{M}$ of about $25 \mathrm{~K}$ toward lower temperature at an external magnetic field of $5 \mathrm{~T}$ were also found in $\mathrm{Ni}_{50-\mathrm{x}} \mathrm{Co}_{\mathrm{x}} \mathrm{Mn}_{32-\mathrm{y}} \mathrm{Fe}_{\mathrm{y}} \mathrm{Ga}_{18}$ for $\mathrm{x}=8$ and $\mathrm{y}=2$ (data not shown). It should be noted here that the $\mathrm{M}(\mathrm{T})$ data at $300 \mathrm{~K}$ for $\mathrm{x}=8, \mathrm{y}=2$ show the large magnetization associated with the austenitic phase. The discrepancy between the ratio of the austenitic and martensitic phases from $\mathrm{M}(\mathrm{T})$ and room temperature XRD data is most likely due to the difference in thermo-magnetic history or a difference in the quantities of stress and defects in bulk $[\mathrm{M}(\mathrm{T})]$ and powder $(\mathrm{XRD})$ samples.
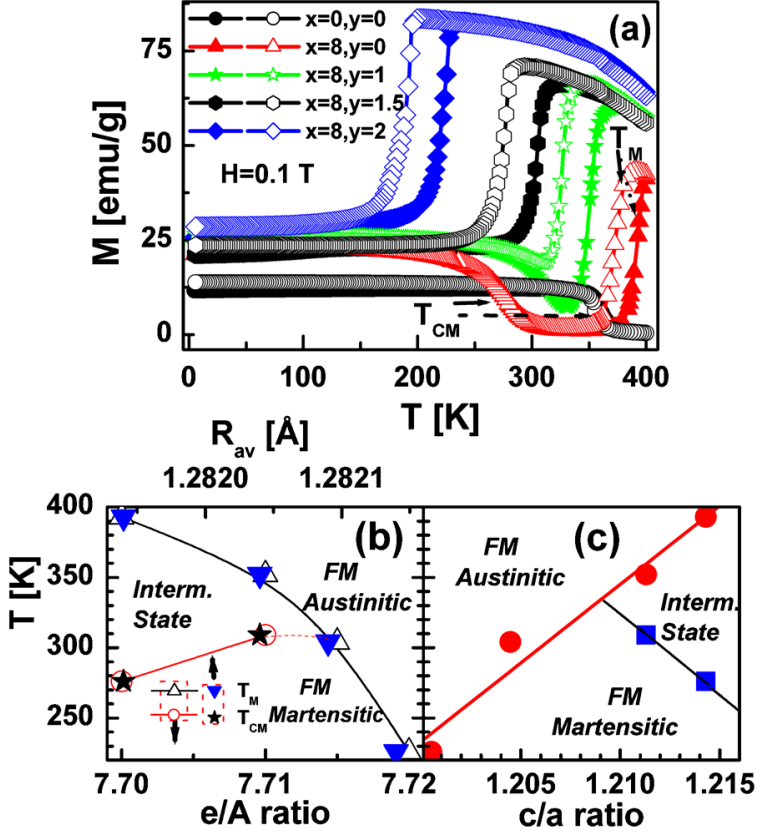

FIG. 2. (Color online) (a) ZFC (closed symbols) and FCC (open symbols) magnetization $[\mathrm{M}(\mathrm{T})]$ for $\mathrm{Ni}_{50-\mathrm{x}} \mathrm{Co}_{\mathrm{x}} \mathrm{Mn}_{32-\mathrm{y}} \mathrm{Fe}_{\mathrm{y}} \mathrm{Ga}_{18}$. Temperature phase diagram as a function of (b) the average metallic radii and e/A ratio, and (c) the c/a ratio for $\mathrm{Ni}_{50-\mathrm{x}} \mathrm{Co}_{\mathrm{x}} \mathrm{Mn}_{32-\mathrm{y}} \mathrm{Fe}_{\mathrm{y}} \mathrm{Ga}_{18}$ at $\mathrm{H}=0.1 \mathrm{~T}$.

The phase diagram for $\mathrm{Ni}_{42} \mathrm{Co}_{8} \mathrm{Mn}_{32-\mathrm{y}} \mathrm{Fe}_{\mathrm{y}} \mathrm{Ga}_{18}$ is shown in Figs. 2(b) and 2(c). As can be seen from Fig. 2(b), three magnetic states can be observed in $\mathrm{Ni}_{42} \mathrm{Co}_{8} \mathrm{Mn}_{32-\mathrm{y}} \mathrm{Fe}_{\mathrm{y}} \mathrm{Ga}_{18}$ : (i) a low temperature FM martensitic phase; (ii) an AFM or PM phase in the intermediate state $\left(\mathrm{T}_{\mathrm{CM}}<\mathrm{T}<\mathrm{T}_{\mathrm{M}}\right)$; and (iii) a high temperature FM austenitic phase. It was found that an increase in the $\mathrm{Fe}$ concentration increases the e/A ratio (or $\mathrm{R}_{\mathrm{av}}$ ) and $\mathrm{T}_{\mathrm{CM}}$, and at a critical value of e/A, $\mathrm{T}_{\mathrm{CM}}$ and $\mathrm{T}_{\mathrm{M}}$ overlappes. $\mathrm{T}_{\mathrm{M}}$ decreases and tends to disappear with increasing e/A ratio. In the XRD phase diagram, an inflection point was observed at $\mathrm{c} / \mathrm{a}=1.21$ [see in Fig. 1(f)]. It can also be seen from Figs. 1(f) and 2 that $\mathrm{Ni}_{42} \mathrm{Co}_{8} \mathrm{Mn}_{32-\mathrm{y}} \mathrm{Fe}_{\mathrm{y}} \mathrm{Ga}_{18}$ undergoes multiple transitions: (i) at $\mathrm{T}_{\mathrm{CM}}$, and (ii) at $\mathrm{T}_{\mathrm{M}}$ when $\mathrm{c} / \mathrm{a}<1.21\left(\mathrm{~T}_{\mathrm{CM}}\right.$ and $\mathrm{T}_{\mathrm{M}}$ overlap when $\left.\mathrm{c} / \mathrm{a}=1.21\right)$. Band structure calculations revealed that tetragonal distortion plays an important role in the martensitic phase stability of Heusler alloys. ${ }^{11}$ Thus, the c/a ratio can be an essential factor that influences the structural transition. The maximum change in e/A $(0.26 \%)$ [or $\mathrm{R}_{\mathrm{av}}(0.016 \%)$ ] is much lower than the maximum change in c/a $(1.38 \%)$ in $\mathrm{Ni}_{42} \mathrm{Co}_{8} \mathrm{Mn}_{32-\mathrm{y}} \mathrm{Fe}_{\mathrm{y}} \mathrm{Ga}_{18}$ [see Figs. 1(f) and 2(b)]. As can be seen from Fig. 2(c), $T_{M}$ and $T_{C M}$ are linear functions of the c/a ratio. Therefore, it is most likely that the c/a ratio is the main factor affecting the observed phase transition temperatures of $\mathrm{Ni}_{42} \mathrm{Co}_{8} \mathrm{Mn}_{32-\mathrm{y}} \mathrm{Fe}_{\mathrm{y}} \mathrm{Ga}_{18}$.

A sharp drop in $\rho(\mathrm{T})$ of more than $40 \%$ was observed at the martensitic transformation (see Fig. 3). The step-like drops and temperature hysteresis observed in $\rho(\mathrm{T})$ at $\mathrm{T}_{\mathrm{M}}$ are the evidences of the first order nature of the transition. The application of magnetic field shifts the jump in resistivity toward low-temperature, following the field-induced shift in $T_{M}$ (see Fig. 3). The shift in $T_{M}$ results in the giant $M R$ (shown in the inset of Fig. 3). As can be seen in the inset of 


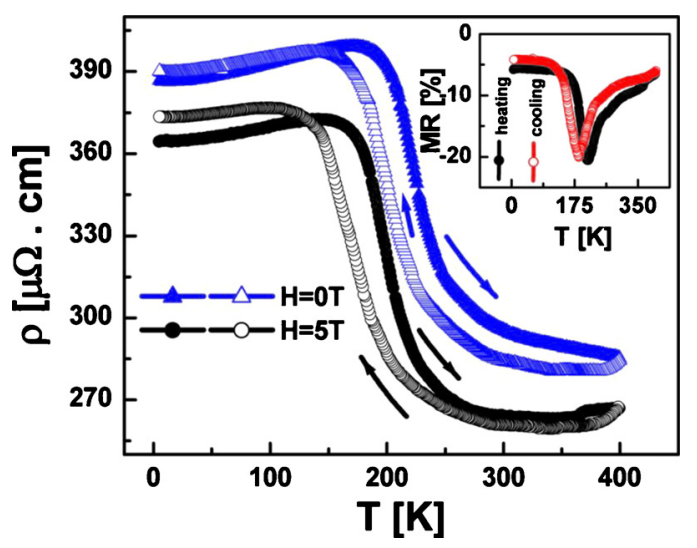

FIG. 3. (Color online) Temperature dependence of the resistivity $\rho(\mathrm{T})$ and MR (inset) for $\mathrm{Ni}_{42} \mathrm{Co}_{8} \mathrm{Mn}_{30} \mathrm{Fe}_{2} \mathrm{Ga}_{18}$ for $\mathrm{H}=0$ and $5 \mathrm{~T}$. Closed and open symbols represents ZFC and FCC $\rho(\mathrm{T})$, respectively. Arrows indicate the direction of the measurement cycles.

Fig. 3, the large $M R \approx-21 \%$ was observed in the vicinity of $\mathrm{T}_{\mathrm{M}}$ for external magnetic field changes $\Delta \mathrm{H}=5 \mathrm{~T}$ for both heating and cooling processes (see Fig. 3).

Typical magnetizing and demagnetizing $\mathrm{M}(\mathrm{H})$ curves for $\mathrm{Ni}_{42} \mathrm{Co}_{8} \mathrm{Mn}_{32-\mathrm{y}} \mathrm{Fe}_{\mathrm{y}} \mathrm{Ga}_{18}(\mathrm{y}=2)$ show the FM behavior with the field hysteresis in the vicinity of $\mathrm{T}_{\mathrm{M}}$ (see Fig. 4). The hysteresis loss (HL) was estimated from the enclosed area between the magnetizing and demagnetizing $\mathrm{M}(\mathrm{H})$ curves and plotted in the inset of Fig. 4. The average HL over the FWHM temperature range was found to be $40 \mathrm{~J} / \mathrm{Kg}$, which is significantly lower than that observed in other Heusler system. ${ }^{2,12}$

Since there are no problematic discontinuity in the $\mathrm{M}(\mathrm{H})$ curves shown in Fig. 4, as suggested by Gschneidner et al., we have applied a Maxwell relation to estimate $\Delta \mathrm{S}_{\mathrm{M}}$ in the vicinity of the FOT and the results are shown in Fig. 5. The maximum estimated $\Delta \mathrm{S}_{\mathrm{M}}$ was found to be $\approx(+) 31 \mathrm{~J} \mathrm{Kg}^{-1} \mathrm{~K}^{-1}$ at $\mathrm{T}=205 \mathrm{~K}$. The $\Delta \mathrm{S}_{\mathrm{M}}$ increases almost linearly with $\Delta \mathrm{H}$ and does not saturate for $\Delta \mathrm{H}=5 \mathrm{~T}$ (see inset of Fig. 5). The RC, which measures the potential of materials to transfer heat between the cold and hot sinks in one ideal refrigeration cycle, ${ }^{8}$ in the vicinity of $\mathrm{T}_{\mathrm{M}}$, was

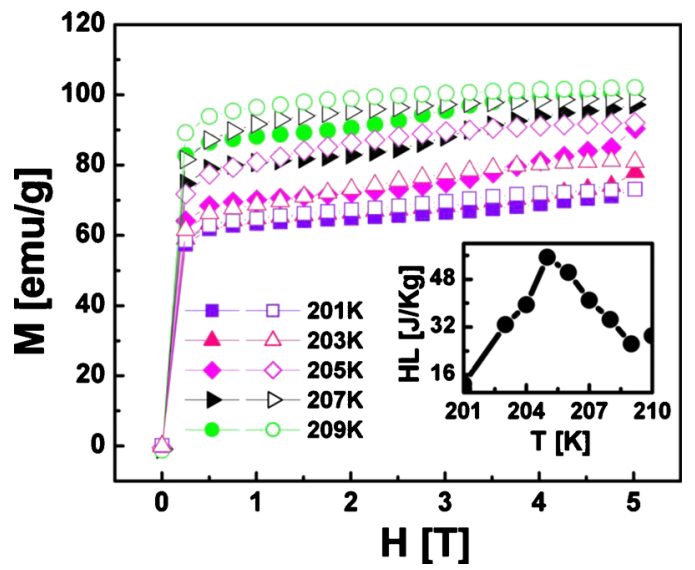

FIG. 4. (Color online) Isothermal magnetization curves $\mathrm{M}(\mathrm{H})$ for $\mathrm{Ni}_{42} \mathrm{Co}_{8} \mathrm{Mn}_{30} \mathrm{Fe}_{2} \mathrm{Ga}_{18}$ in the vicinity of $\mathrm{T}_{\mathrm{M}}$. The inset shows the calculated $\mathrm{HL}$ in the vicinity of $\mathrm{T}_{\mathrm{M}}$.

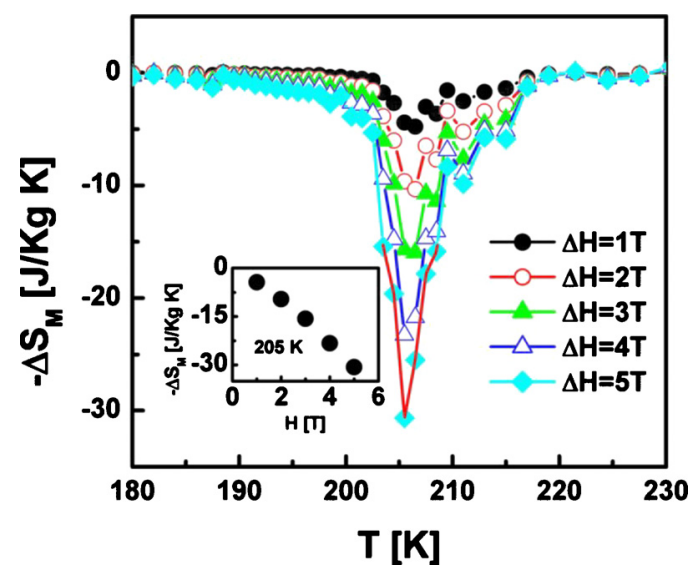

FIG. 5. (Color online) Magnetic entropy change $\left(\Delta \mathrm{S}_{\mathrm{M}}\right)$ of $\mathrm{Ni}_{42} \mathrm{Co}_{8} \mathrm{Mn}_{30} \mathrm{Fe}_{2} \mathrm{Ga}_{18}$ with temperature in the vicinity of $\mathrm{T}_{\mathrm{M}}$. The inset shows the peak value of $\Delta \mathrm{S}_{\mathrm{M}}$ of $\mathrm{Ni}_{42} \mathrm{Co}_{8} \mathrm{Mn}_{30} \mathrm{Fe}_{2} \mathrm{Ga}_{18}$ as a function of the change in the applied magnetic field.

found to be $110 \mathrm{~J} / \mathrm{Kg}$ for a magnetizing field of $5 \mathrm{~T}$. Taking into account HL (see inset of Fig. 4) in the vicinity of the FOT, the net RC was calculated by subtracting the average $\mathrm{HL}$ from the uncorrected $\mathrm{RC}$ value. The average $\mathrm{HL} \approx 40$ $\mathrm{J} / \mathrm{Kg}$ was calculated over the same temperature range as that of the FWHM of the $\Delta \mathrm{S}_{\mathrm{M}}$. The corresponding net RC value at FOT was found to be $70 \mathrm{~J} / \mathrm{Kg}$ when $\mathrm{HL}$ were taken into account.

In conclusion, the observed $\mathrm{RC}$, inverse $\Delta \mathrm{S}_{\mathrm{M}}$ and $\mathrm{MR}$, low $\mathrm{HL}$ and the tunability of $\mathrm{T}_{\mathrm{M}}$ through variations in $\mathrm{Fe}$ concentration make the $\mathrm{Ni}_{50-\mathrm{x}} \mathrm{Co}_{\mathrm{x}} \mathrm{Mn}_{32-\mathrm{y}} \mathrm{Fe}_{\mathrm{y}} \mathrm{Ga}_{18}$ system an attractive potential magnetic material when compared to other Heusler alloys with large hysteresis in the vicinity of $\mathrm{T}_{\mathrm{M}}$.

This research was supported by Research Corporation (RA-0357) and by the Office of Basic Energy Sciences, U.S. DOE (Contract No. DE-FG02-06ER46291).

${ }^{1}$ T. Krenke, E. Duman, M. Acet, E. F. Wassermann, X. Moya, L. Mañosa, and A. Planes, Nature Mater. 4, 450 (2005).

${ }^{2}$ A. K. Pathak, M. Khan, I. Dubenko, S. Stadler, and N. Ali, Appl. Phys. Lett. 90, 262504 (2007).

${ }^{3}$ A. K. Pathak, M. Khan, B. R. Gautam, S. Stadler, I. Dubenko, and N. Ali, J. Appl. Phys. 103, 07F315 (2008).

${ }^{4}$ A. N. Vasil'ev, A. D. Bozhko, V. V. Khovailo, I. E. Dikshtein, V. G. Shavrov, V. D. Buchelnikov, M. Matsumoto, S. Suzuki, T. Takagi, and J. Tani, Phys. Rev. B 59, 1113 (1999).

${ }^{5}$ S. Fabbrici, F. Albertini, A. Paoluzi, F. Bolzoni, R. Cabassi, M. Solzi, L. Righi, and G. Calestani, Appl. Phys. Lett. 95, 022508 (2009).

${ }^{6}$ C. Jiang, J. Wang, P. Li, A. Jia, and H. Xu, Appl. Phys. Lett. 95, 012501 (2009)

${ }^{7}$ S. Y. Yu, Z. X. Cao, L. Ma, G. D. Liu, J. L. Chen, G. H. Wu, B. Zhang, and X. X. Zhang, Appl. Phys. Lett. 91, 102507 (2007).

${ }^{8}$ K. A. Gschneidner, Jr., V. K. Pecharsky, and A. O. Tsokol, Rep. Prog. Phys. 68, 1479 (2005).

${ }^{9}$ W. B. Pearson, The Crystal Chemistry and Physics of Metals and Alloys (Wiley, New York, 1972).

${ }^{10}$ S. Aksoy, M. Acet, P. P. Deen, L. Mañosa, and A. Planes, Phys. Rev. B 79, 212401 (2009).

${ }^{11}$ A. Ayuela, J. Enkovaara, K. Ullakko, and R. M. Nieminen, J. Phys.: Condens. Matter 11, 2017 (1999).

${ }^{12}$ A. K. Pathak, I. Dubenko, S. Stadler, and N. Ali, J. Phys. D: Appl. Phys. 41, 202004 (2008). 